\title{
Characterisation of connection mechanisms within road safety barriers
}

\author{
D. A. F. Bayton ${ }^{1,2}$, M. Lawrence ${ }^{2} \&$ G. Fourlaris ${ }^{1}$ \\ ${ }^{\prime}$ Materials Research Centre, University of Wales, Swansea, UK \\ ${ }^{2}$ Corus Construction and Engineering Products, UK
}

\begin{abstract}
The performance of road safety barrier connections is not directly linked to advances in vehicle technology. The UK government has recently released a new vehicle restraint systems specification that has resulted in the transfer of design responsibility to industrial safety barrier manufacturers. Road safety barrier connections utilise slotted holes that are perpendicular to the direction of the safety barrier beam profile. The bolt is significantly smaller than the slot and different performance outcomes can result from the positioning and preloading of the bolt with relation to the slotted hole.

Finite element models have been constructed and validated using theoretical data as well as experimental data produced using a series of laboratory tests. The finite element model has been based on a standard test coupon that incorporates a full size safety barrier connection slot to industry standard dimensions.

The laboratory results showed that the maximum force and displacement of the connections are comparable to the finite element model predictions. Comparisons made between the independent testing of safety barrier connections and the laboratory test coupons indicated that there was a good preliminary correlation between the computer model and the laboratory test coupons. Subsequently a simplified approach has been applied to the finite element modelling method with respect to connection movement mechanisms.
\end{abstract}

Keywords: safety barrier, crash, steel, finite element analysis, connection, fastener. 


\section{Introduction}

The use of bolted joints to connect structural members together and to transfer in-plane forces between them has been extensively employed in civil, mechanical and aeronautic structures $\mathrm{Su}$ and Siu [1]. Bolted connections are extensively used in roadside safety barriers and their characteristics can directly affect the performance of the whole roadside barrier system. Corrugated beam safety barriers use double row bolted lap joints to make the connection between beam lengths. Bolted joints that allow for slippage are widely used on roadside structures Reid and Hiser [2]. When an errant vehicle impacts the safety barrier system, slip may be observed at various connections. When a vehicle impacts a safety barrier, a considerable amount of energy is absorbed by the barrier to arrest the vehicle before allowing it to depart the barrier in a safe manner. Some of the crash energy is forced along the total beam length. Previous test work conducted by Corus has shown that as much as $340 \mathrm{kN}$ of force is directed along the barrier and through the connection joints Bayton et al [3]. Due to manufacturing and assembly tolerances incorporated into the build phase of each safety barrier, an amount of slippage occurs during a crash. As a result, the amount of torque and resulting clamping force exerted onto a joint has a direct impact on safety barrier performance. In terms of performance, the deflection of a barrier can change due to joint movement increasing the barrier deflection distance. Working width is a desirable feature when selecting a safety barrier design BSI [4]. Generally, a narrow working width would mean a narrower carriage way central median, but conversely this may result in greater injuries being sustained by the vehicle's occupants due to stiffer system characteristics.

In general, bolted joints that will slip are mechanical connections between two components that allow for movement of one of the components in relation to the other along a specified direction Reid and Hiser [2]. However in the case of corrugated safety barrier connections the slot is perpendicular to the barrier direction to aid with the construction of the barrier system. Nevertheless the joint does move upon impact and this occurs because the slotted hole is significantly bigger than the bolt diameter as well as plastic deformation of the actual safety barrier material Bayton et al [3].

While there has been a great incentive to improve the prospect of occupant survivability through improvements to the vehicle design, it would seem safety barrier designs have remained stagnant in the UK for several decades. With this in mind the end goal of this research is to ultimately provide a better safety barrier system for use on Europe's roads.

This will be done by conducting research into the movement characteristics of safety barrier connections. Therefore it is the aim of this research paper to understand the movement characteristics of safety barrier joints by identifying the slip/movement characteristics of test specimen coupons in a laboratory and correlate this to finite element computer modelling predictions. 


\section{Finite element modelling}

Due to research limitations into movement mechanisms of safety barrier connections, non-linear finite element analysis was used to develop an initial modelling technique for a safety barrier connection. The finite element simulation of bolted connections is generally complicated because the problem is three dimensional in nature. In addition, combined non-linear phenomena like material and geometrical nonlinearities, friction, slippage, contact bolt-plate interaction and fracture have to be reproduced Bursi and Jaspart [5]. Abaqus finite element code was used for this analysis. The model was constructed and meshed using Abaqus CAE standard and explicit computer software. The test plates were modelled using shell elements which are principally used for the structures that in one direction, especially the thickness are considerably less than the other dimensions Abaqus [6]. This lends itself well to subsequent finite element modelling work involving sheet metal assemblies. Consequently, the use of conventional shell elements was used for this analysis. Abaqus allows the use of conventional shell element models that represent the actual material thickness as a definition of the material cross section properties. This feature also ensures that the models are kept relatively small as to not use a great deal of computational resource to solve each analysis. There has been a significant amount of computer modelling work conducted by Reid and Hiser [2] and this has focussed on detailed slip based models that give an increased accuracy coupled with large amounts of component detail. Alternatively this research paper describes how a simplified model can be used which could still achieve good useable accuracy when incorporated into a global safety barrier model.

Boundary conditions were introduced to simulate the laboratory conditions of the tensile test. Boundary conditions restrict or allow movement and rotation around the $\mathrm{x}, \mathrm{y}$ and $\mathrm{z}$ axis of the constructed model. Abaqus also utilises a mesh independent fastener function. These fasteners have particular elements that allow simple connections to be made between surfaces or objects. The fastener function was coupled with a connector element that additionally, can incorporate very complex mechanical behaviour such as elasticity, damping, plasticity, damage and friction as part of the finite element model. All of these properties are present in a bolted connection and with the exception of damage they may well be present from the time the joint is first assembled.

To complement the connection characteristics of the finite element model, true stress and strain values were input for the Carbon Manganese (CMn) steel grade that was manufactured by Corus Strip Products (UK) Ltd in accordance to BSEN 10025-1-2004 Hot rolled products for structural steels (BSI [7]). The chemical composition is shown in Table 1.

True stress and strain values differ from the more widely utilised engineering stress and strain values because they do not take into consideration the change in cross sectional area or "diffuse" necking of the material specimen under test. Therefore when undertaking an analysis that will almost certainly involve the 
Table 1: Chemical composition of S275 steel grade.

\begin{tabular}{|c|c|c|c|c|c|c|c|c|}
\hline $\begin{array}{l}\text { Steel } \\
\text { Grade }\end{array}$ & $\begin{array}{l}\text { C } \\
\text { Max. }\end{array}$ & $\begin{array}{l}\text { Mn } \\
\text { Max. }\end{array}$ & $\begin{array}{l}\mathbf{P} \\
\text { Max. }\end{array}$ & $\begin{array}{l}\mathbf{S} \\
\text { Max. }\end{array}$ & $\begin{array}{l}\mathbf{S i} \\
\text { Max }\end{array}$ & $\begin{array}{l}\text { N1,2 } \\
\text { Max }\end{array}$ & $\begin{array}{l}\text { Nb } \\
\text { Min- } \\
\text { Max } \\
\end{array}$ & $\begin{array}{l}\mathbf{V} \\
\text { Min- } \\
\text { Max }\end{array}$ \\
\hline S275 & 0.25 & 1.60 & 0.05 & 0.05 & 0.50 & - & 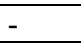 & - \\
\hline \multicolumn{9}{|c|}{$\begin{array}{l}\text { Notes: } \\
\text { It is permissible to exceed the specified values provided that for each increase of } 0.0015 \\
\text { nitrogen the phosphorous maximum content will be reduced by } 0.005 \% \text {; the nitrogen content of } \\
\text { the ladle analysis, however, shall not be more than } 0.012 \% \text {. } \\
\text { The maximum value for nitrogen does not apply of the chemical composition shows a minimum } \\
\text { total aluminium content of } 0.020 \% \text { or if sufficient other nitrogen-binding elements are present } \\
\text { The nitrogen-binding elements shall be mentioned in the inspection document. } \\
\text { Values are in weight percentages }\end{array}$} \\
\hline
\end{tabular}

plastic deformation of the steel sheet, extrapolated stress/strain curves must be calculated to return realistic stress/strain characteristics properties for the whole analysis.

\section{Experimental procedure}

The purpose for the test program was to validate the relationship between the laboratory testing and finite element models. All samples were batch hot dip galvanised coated and followed the exact manufacturing route as for a safety barrier beam. Furthermore galvanised coatings are generally known to significantly reduce the fiction coefficient of mating surfaces Reid and Hiser [2]. A real crash scenario would use a strain rate near to $280 \mathrm{~mm} / \mathrm{sec}$ Bayton et al [3]. However at this stage such parameters were not practical. Therefore in order to test the samples with a certain amount of focus on a typical reality based strain rate, the extension rates of $1 \mathrm{~mm} / \mathrm{sec}$ and of $10 \mathrm{~mm} / \mathrm{sec}$ were chosen as the basis of comparison for the test.

All of the equipment used in the subsequent tests was supplied by Corus RD\&T. In particular the following instruments were employed.

- DARTEC Tensile Testing Machine

- $2000 \mathrm{kN}$ load cell

- System 5000 Data logging equipment

- Calibrated torque wrench

To ensure that there was as much uniformity as possible in the bolted connection a procedure was formulated prior to the commencement of any test work. Accompanying the test procedure were design drawings of the bolted joint assembly, which could be read in conjunction with a formal test method. Experimental test coupons were designed and manufactured as shown in Figure 1 and Figure 2. Each sheet component of the test coupons featured a standard safety barrier slot fixed about the centre line of the test coupon. Each slot was situated at a distance of $21.5 \mathrm{~mm}$ from the edge of the test coupon plate. The test coupon was assembled with M16 bolts conforming to specification ISO-898 (BSI [8]). Each bolt was tightened using a torque setting of $100 \mathrm{Nm}$ to give better 
preload accuracy and allow for the effect of friction between the nut and bolt threads as well as the washer faces. Bickford [10], Oberg et al [9] and Shilgley and Mischke [11]

Two types of connections were assembled for test. These were joints that were unable to move or slip prior to plastic deformation of the steel sheet and joints that would be allowed to move or slip prior to plastic deformation of the steel sheet. In effect optimum connection joints were tested along with connection joints that included undesired features to understand the effect of the slip characteristic.

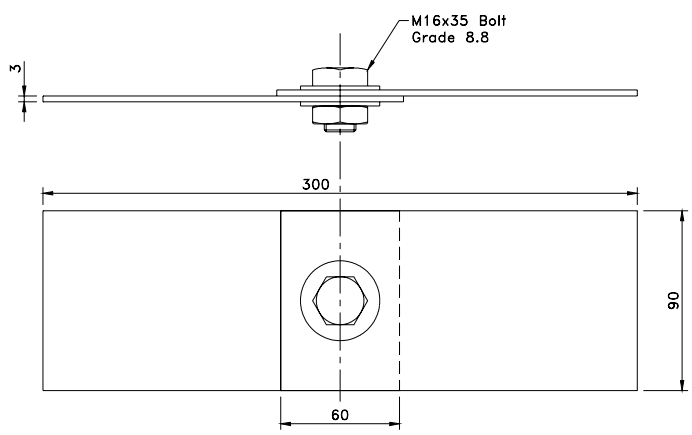

Figure 1: Single bolt connection detail.

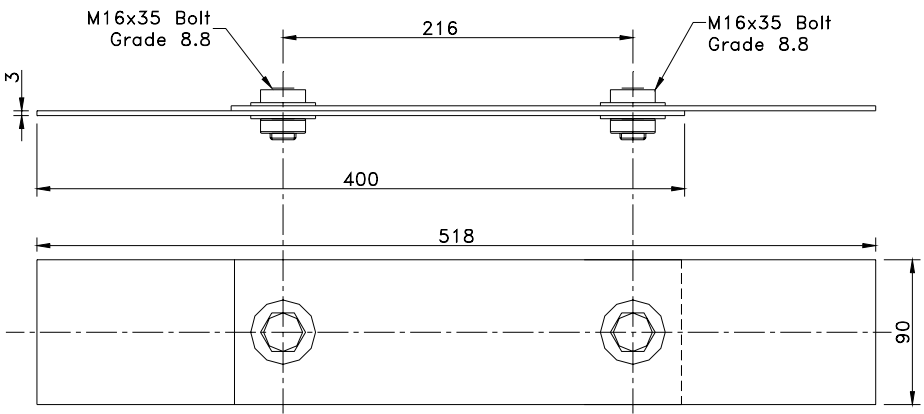

Figure 2: Double bolt connection detail.

\section{Results}

To check the accuracy of both finite element models a series of laboratory tests were conducted. The twelve no slip tests that were conducted are summarised in Table 2. The twelve slip tests are summarised in Table 3. In the case of the double bolt specimens the failure mode for each slot from bottom to top 
respectively has been recorded. As well as the maximum force the force at $3 \mathrm{~mm}$ displacement has been presented. This is because after $3 \mathrm{~mm}$ extension the connection begins to catastrophically fail due to excessive plastic deformation of the slot wall. In the case of the slip connection this figure is $7 \mathrm{~mm}$. Two failure modes were observed in the post test coupons. Plane out shear and tearing of the slot occurred in all of the test specimens Minguez and Vogwell [12]. The observed failure modes are illustrated in Figure 3.

Table 2: $\quad$ Results for single and double bolt connection coupons without slip.

\begin{tabular}{|c|c|c|c|c|c|c|}
\hline Connection & $\begin{array}{c}\text { Coupon } \\
\text { ID }\end{array}$ & $\begin{array}{c}\text { M/C Crosshead speed } \\
\mathrm{mm} / \mathrm{sec}\end{array}$ & \begin{tabular}{|c|}
$\begin{array}{c}\text { Force at 3mm } \\
(\mathrm{kN})\end{array}$ \\
\end{tabular} & $\begin{array}{c}\text { Max Force } \\
(\mathrm{kN})\end{array}$ & $\begin{array}{c}\text { Extension } \\
(\mathrm{mm})\end{array}$ & Failure Mode \\
\hline Single & NS1 & 1 & 24.11 & 35.52 & 10.18 & Plane Out Shear \\
\hline Single & NS2 & 1 & 23.87 & 34.36 & 9.13 & Plane Out Shear \\
\hline \multirow[t]{2}{*}{ Single } & NS3 & 1 & 25.88 & 37.90 & 12.03 & Plane Out Shear \\
\hline & & Mean & 24.62 & 35.93 & 10.45 & \\
\hline Single & NS4 & 10 & 24.72 & 31.86 & 7.50 & Plane Out Shear \\
\hline Single & NS5 & 10 & 22.22 & 34.30 & 10.09 & Plane Out Shear \\
\hline \multirow[t]{3}{*}{ Single } & NS6 & 10 & 24.60 & 39.00 & 14.79 & Tear \\
\hline & & Mean & 23.85 & 35.05 & 10.79 & \\
\hline & & Mean Overall & 24.23 & 35.49 & 10.62 & \\
\hline Double & Double1 & 1 & 50.67 & 66.78 & 7.67 & Plane Out Shear/Plane Out Shea \\
\hline Double & Double2 & 1 & 52.80 & 66.78 & 8.74 & Plane Out Shear/Plane Out Shea \\
\hline \multirow[t]{2}{*}{ Double } & Double3 & 1 & 52.38 & 73.43 & 10.94 & Plane Out Shear/Plane Out Shea \\
\hline & & Mean & 51.95 & 69.00 & 9.12 & \\
\hline Double & Double4 & 10 & 47.74 & 75.69 & 11.79 & Plane Out Shear/Tear \\
\hline Double & Double5 & 10 & 47.37 & 74.11 & 17.58 & Tear/Tear \\
\hline \multirow[t]{3}{*}{ Double } & Double6 & 10 & 51.46 & 73.56 & 12.01 & Plane Out Shear/Tear \\
\hline & & Mean & 48.85 & 74.45 & 13.79 & \\
\hline & & Mean Overall & 50.40 & 71.73 & 11.45 & \\
\hline
\end{tabular}

Table 3: $\quad$ Results for single and double bolt connection coupons with slip.

\begin{tabular}{|c|c|c|c|c|c|c|}
\hline Connection & $\begin{array}{c}\text { Coupon } \\
\text { ID }\end{array}$ & $\begin{array}{c}\text { M/C Crosshead speed } \\
\mathrm{mm} / \mathrm{sec}\end{array}$ & \begin{tabular}{|c|}
$\begin{array}{c}\text { Force at } 3 \mathrm{~mm} \\
(\mathrm{kN})\end{array}$ \\
\end{tabular} & $\begin{array}{c}\text { Max Force } \\
(\mathbf{k N})\end{array}$ & $\begin{array}{c}\text { Extension } \\
(\mathrm{mm})\end{array}$ & Failure Mode \\
\hline Single & Slip1 & 1 & 25.94 & 37.42 & 17.56 & Plane Out Shear \\
\hline Single & Slip2 & 1 & 25.88 & 34.43 & 12.15 & Plane Out Shear \\
\hline \multirow[t]{2}{*}{ Single } & Slip3 & 1 & 24.54 & 36.26 & 16.07 & Plane Out Shear \\
\hline & & Mean & 25.45 & 36.04 & 15.26 & \\
\hline Single & Slip4 & 10 & 24.60 & 38.50 & 17.43 & Tear \\
\hline Single & Slip5 & 10 & 26.92 & 37.79 & 14.27 & Plane Out Shear \\
\hline \multirow[t]{3}{*}{ Single } & Slip6 & 10 & 27.23 & 35.34 & 12.92 & Plane Out Shear \\
\hline & & Mean & 26.25 & 37.21 & 14.87 & \\
\hline & & Mean Overall & 25.85 & \begin{tabular}{l|l}
36.62 \\
\end{tabular} & 15.07 & \\
\hline Double & Dslip1 & 1 & 50.85 & 68.61 & 14.02 & Tear/Plane Out Shear \\
\hline Double & Dslip2 & 1 & 56.95 & 71.48 & 14.80 & Tear/Plane Out Shear \\
\hline \multirow[t]{2}{*}{ Double } & Dslip3 & 1 & 58.17 & 71.24 & 12.88 & Tear/Plane Out Shear \\
\hline & & Mean & 55.33 & 70.44 & 13.90 & \\
\hline Double & Dslip4 & 10 & 51.22 & 72.15 & 20.41 & Plane Out Shear/Tear \\
\hline Double & Dslip5 & 10 & 51.28 & 69.96 & 17.12 & Tear/Plane Out Shear \\
\hline \multirow[t]{3}{*}{ Double } & Dslip6 & 10 & 51.34 & 75.08 & 15.84 & Plane Out Shear/Plane Out Shear \\
\hline & & Mean & 51.28 & 72.40 & 17.79 & \\
\hline & & Mean Overall & 53.30 & \begin{tabular}{l|l}
71.42 \\
\end{tabular} & 15.84 & \\
\hline
\end{tabular}

In Figures 4-7 the loading and relative displacement are presented. The overall reactions for the four models are plotted and the output from the finite element model is included for comparison. Joint slip was incorporated into the finite element model because this is an unwanted feature of the design but it also needed due consideration in the testing phase of this research. This was to ascertain if connection joint slip had an adverse effect on connection joint strength. 


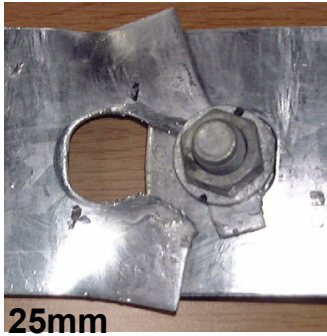

1. Plane Out Shear

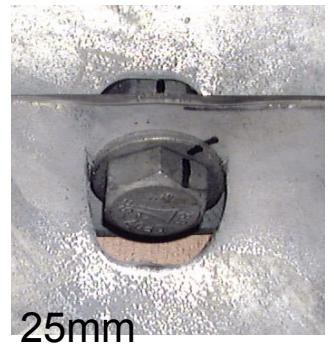

2. Tear

Figure 3: $\quad$ Observed failure modes in test specimens.

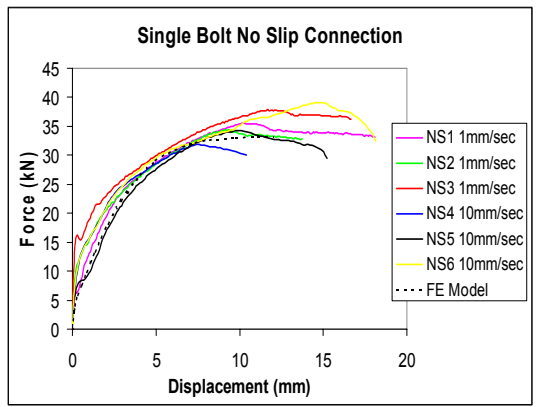

Figure 4: $\quad$ Single bolt connection.

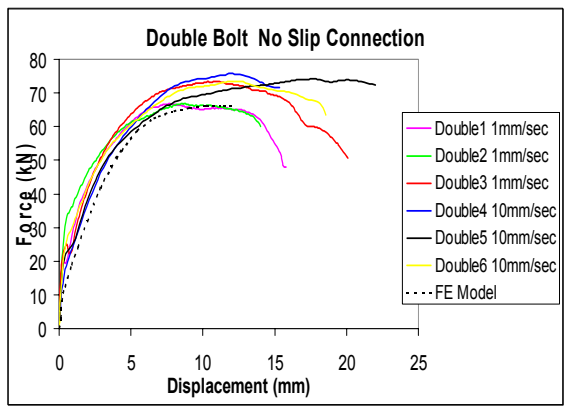

Figure 5: Double bolt connection.

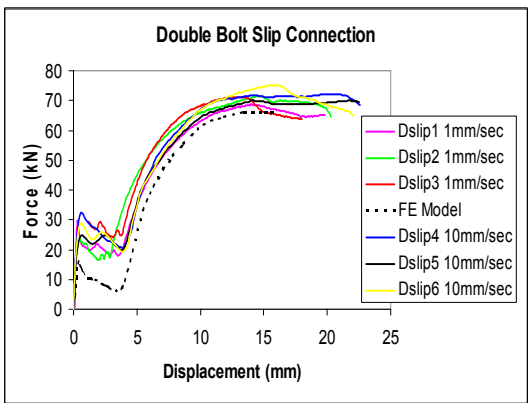
Figure 6: $\begin{aligned} & \text { Single bolt } \\ & \text { connection. }\end{aligned}$

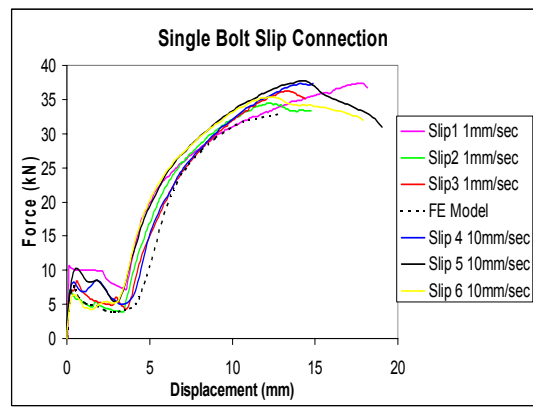

slip

The plots in Figures 4-7 demonstrate that there is a higher initial stiffness in both connections than has been predicted in the finite element model. The finite element analysis predicted a maximum force of $33.1 \mathrm{kN}$ with the mean maximum force from the laboratory results being $35.49 \mathrm{kN}$ and $36.62 \mathrm{kN}$ for the single bolt no slip and slip models respectively. As the complexity of the connection 
increases, i.e. from one bolt to two bolts so the initial stiffness increases along with the maximum UTS obtained. The finite element model for the two bolt connection returns a result of $66.21 \mathrm{kN}$ whereas the mean maximum force from testing is $71.73 \mathrm{kN}$ for the double connection with no slip and $71.42 \mathrm{kN}$ for the connection the was allowed to slip. There is a larger displacement of the specimen connection when compared to the finite element model. Joint slip has little effect on the overall strength of the connection because of the small difference between the maximum forces of the no slip and slip induced connection specimens.

\section{Discussion}

Previous work conducted by Reid and Hiser [2] concentrated on joints that were intended to slip under a given load. It is the resultant joint movement that returns a safe or failure mode of operation for the connection joint. Therefore the correct torque and preload is of prime importance to connection joint operation. Conversely, slip or movement in safety barrier connections is an unwanted feature of the design. Preload calculations conducted as part of this research using a procedure detailed by Shigley and Mischke [11] are only intended as an estimate and the only true measurement could be taken with either ultrasonic equipment or load cell instrumentation. The calculations also make the assumption that the mating parts and lubricant are clean and free from any debris that may hinder the tightening process. Steel shear connections are designed to transfer the load from one member to another Astaneh-Asl et al [13]. With this mind any slip between connecting members will affect this transfer of load. In the case of the test coupons, the Ultimate Tensile Strength (UTS) was deferred by means of increased displacement in the connection. Build tolerances exist because in reality each safety barrier installation is slightly different and the barrier slot profile has to allow for this.

The connection joint slips when impacted by an errant vehicle and this leads to a performance related characteristic that needs to be fully understood. Removal of this characteristic will lead to a stiffer safety barrier system, which could be deemed good in terms of dynamic barrier deflection or bad with regard to vehicle occupant safety (BSI [4]).

When the connections failed two failure modes were observed and these are consistent with work carried out by Ray et al [14] when conducting full-scale safety barrier tensile tests. The failure modes also agree with work carried out by Rogers and Hancock [15] and Minguez and Vogwell [12] although Rogers' work featured steel sheets less than $1.0 \mathrm{~mm}$ of similar grade to the current safety barrier material. All of the failure modes are ductile involving unrestrained yielding of the steel sheet. Astaneh-Asl et al [13]

\section{Conclusions}

Twenty four bolted lap joint connections have been tensile tested at varying crosshead speeds. The purpose of the tests was to reliably model the same linear 
displacement for a given force magnitude. Once the initial calibration of the single connection model was completed, the double connection model returned conservative results when compared to the actual laboratory results. This is perhaps a welcome result when considering the end product.

Consequently the clamping load exerted on the joint is not only important for decreasing joint slip but it must maintain structural integrity over time (Reid and Hiser [2]). If connection slip were to be removed as much as practically possible then this would result in a system with a stiffer characteristic upon impact of an errant vehicle which in turn could transfer the crash load between safety barrier beams more effectively.

The initial stiffness observed in the connection is different to the FE model and this may be down to the way in which the true stress and strain data was derived from the engineering tensile test data returned from preliminary tensile testing (BSI [16]). Based on this observation it will be necessary to re-examine the initial test data and the method of extrapolation for the results to ensure that the tabular data used by the FE model is adequate.

The effect of the spacing between the double bolt test coupons may have an effect on overall connection UTS as well as the placement of the first slot with relation to the edge of the test coupon. Connection joint slip defers the UTS of the connection in terms of linear displacement, but has little or no effect on the UTS.

Although the connection displacement is recorded as being as much as $20 \mathrm{~mm}$ in some cases of the laboratory results, the connection can be considered to have catastrophically failed at a displacement of approximately $3 \mathrm{~mm}$ for a no slip connection and approximately $7 \mathrm{~mm}$ for a slip connection. Full-scale safety barrier tensile tested conducted by Ray et al [14] confirms that the safety barrier beams failed with a connection displacement of less than $25 \mathrm{~mm}$.

The current rate of displacement being $1 \mathrm{~mm} / \mathrm{sec}$ to $10 \mathrm{~mm} / \mathrm{sec}$ has little effect on connection joint response and it will be necessary to increase the rate of displacement for further testing to examine if the connection response or UTS changes as a results of increase tensile rates.

\section{References}

[1] Su, R.K.L \& Siu, W.H. Non-linear Response of Bolt Groups Under Inplane Loading. Engineering Structures (Article In Press). Elsevier. 2006.

[2] Reid, J.D. \& Hiser, N.R. Detailed Modelling of Bolted Joints with Slippage. Finite Elements in Analysis and Design. 9 (1), pp. 547-562. 2005.

[3] Bayton, D.A.F. Fourlaris, G. \& Jones, T.B. Safety Barrier Connection Joint Post Test Analysis. Materials and Design (Approved for publication). Elsevier Publishing. 2006.

[4] British Standards Institute. BS EN1317-1-2-3-4: Road Restraint Systems. London:BSI Publications. 2000.

[5] Bursi, O.S. \& Jaspart, J.P. Benchmarks for Finite Element Modelling of Bolted Steel Connections. Journal of Constructional Steel Research. 43 (1-3), pp. 17-42. 1997. 
[6] Abaqus Inc. Abaqus Users Manual. Providence:ABAQUS inc. 2005

[7] British Standards Institute. BSEN 10025-1:2004. Hot rolled Products of Structural Steel. London: BSI Publications. 2004.

[8] British Standards Institute. ISO898-1 Mechanical Properties of Fasteners Manufactured from Carbon Steel and Alloy Steel. London:BSI Publications. 1999.

[9] Oberg, E. Jones, F.D. Horton, H.L. \& Ryffel, H.H. Machinery's Handbook. 25th edn. New York: Industrial Press Inc. 1996.

[10] Bickford, J.H. An Introduction to the Design and Behaviour of Bolted Joints. New York:Marcell Dekker Inc. 1974.

[11] Shigley, J.E. \& Mischke, C.R. Mechanical Engineering Design. 5th edn. London:McGraw-Hill. 1989.

[12] Minguez, J.M. \& Vogwell, J. Effect of Torque Tightening on the Fatigue Strength of Bolted Joints. Engineering Failure Analysis. 13 (8), pp. 1410 1421. 2006.

[13] Astaneh-Asl, A. \& Liu, J \& McMullin, K.M. Behaviour and Design of Single Plate Shear Connections. Journal of Constructional Steel Research. 58 (5-8), pp. 1121-1141. 2002.

[14] Ray, M.H. Engstrand, \& K. Plaxico, C.A. Performance of W-Beam splices. Massachussetts:Worcester Polytechnic Institute. 2001.

[15] Rogers, C.A. \& Hancock, G.J. Bolted Connection Design for Sheet Steels Less Than 1.0mm Thick. Journal of Constructional Steel Research. 51 (2), pp. 123-146. 1999.

[16] British Standards Institute. BSEN 10002-1:2001 Metallic Materials Testing - Part 1 Method of Test at Ambient Temperature London:BSI Publications. 2001. 